- Supporting Information -

\title{
Computational screening of indirect gap semiconductors for potential photovoltaic absorbers
}

\author{
Youngho Kang, ${ }^{*}{ }^{\dagger}$ Yong Youn, ${ }^{\S}$ Seungwu Han, ${ }^{\S}$ Jiwon Park, ${ }^{\dagger}$ and Chang-Seok $\mathrm{Oh}^{\dagger}$ \\ ${ }^{\dagger}$ Materials data center, Korea Institute of Materials Science, Changwon 51508, Korea \\ §Department of Materials Science and Engineering, Seoul National University, Seoul o8826, Korea
}

*E-mail: thehoya84@gmail.com 

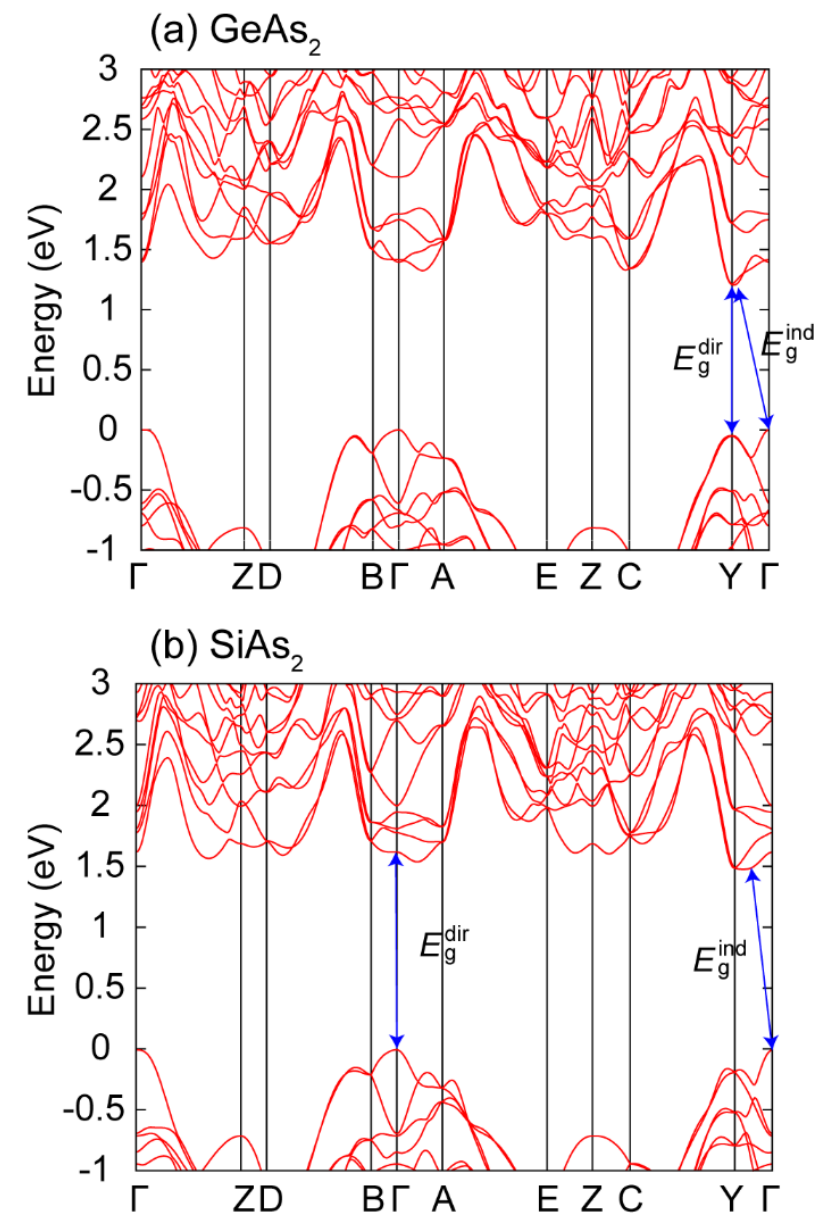

(c) $\mathrm{NaSbS}_{2}$

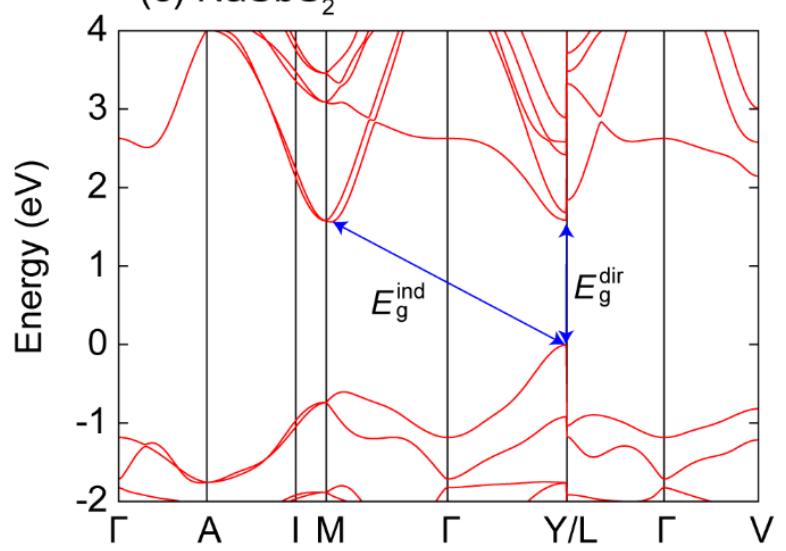

Figure S1. Band structures of (a) $\mathrm{GeAs}_{2}$, (b) $\mathrm{SiAs}_{2}$, and (c) $\mathrm{NaSbS}_{2}$ obtained using the HSEo6 functional. The valence band maximum is set to o for all of the band structures. 


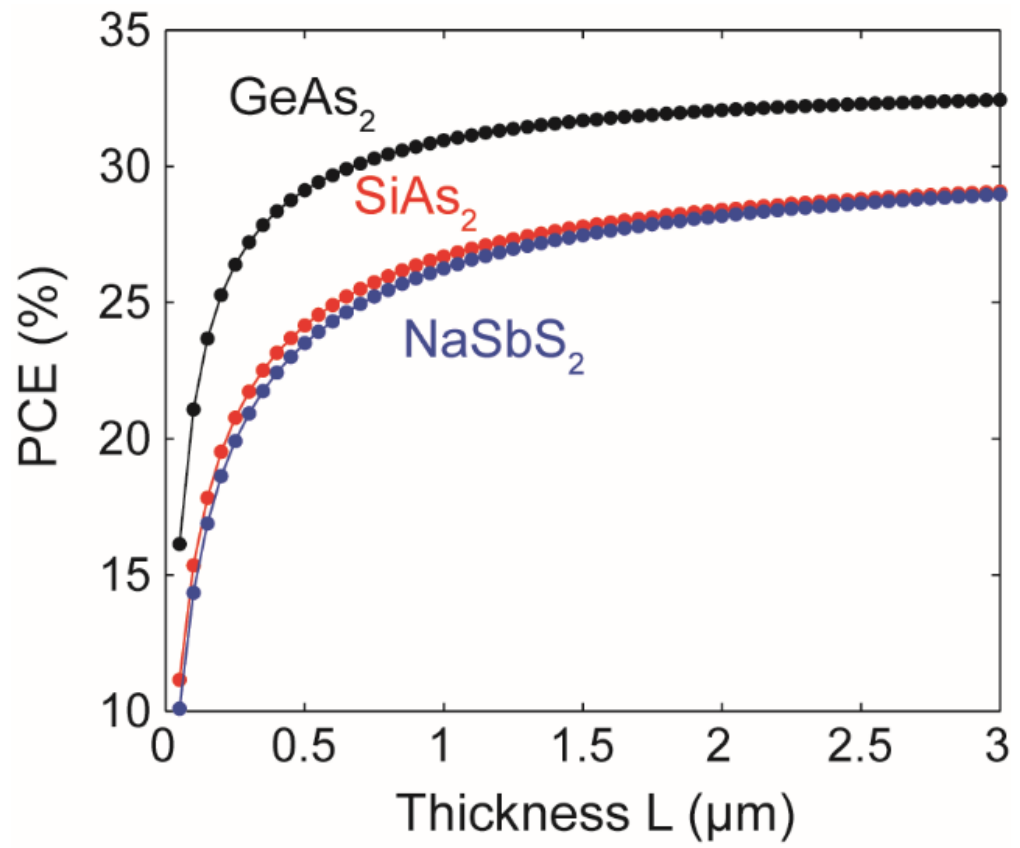

Figure $\mathrm{S}_{2}$. The SLME as a function of thin film thickness for $\mathrm{GeAs}_{2}, \mathrm{SiAs}_{2}$, and $\mathrm{NaSbS}_{2}$. 


\section{Chemical potential of constituting elements}

The defect formation energy depends on chemical potentials of constituting elements involved in the formation of a defect and their values should be bounded to ensure the phase stability of materials. To be specific, in the case of binary systems such as $\mathrm{GeAs}_{2}, \mu_{\mathrm{Ge}}=0 \mathrm{eV}$ and $\mu_{\mathrm{As}}=1 / 2 \Delta H\left[\mathrm{GeAs}_{2}\right]$ under the Ge-rich condition while $\mu_{\mathrm{As}}=0 \mathrm{eV}$ and $\mu_{\mathrm{Ge}}=\Delta H\left[\mathrm{GeAs}_{2}\right]$ under the As-rich condition, where $\Delta H\left[\mathrm{GeAs}_{2}\right]$ is the heat of formation of $\mathrm{GeAs}_{2}$. Considering GeAs as an additional limiting phase does not alter the results. Note that the chemical potentials are referenced to ones in the most stable elemental phases. The same principle is applicable to determining the limit of chemical potentials for $\mathrm{SiAs}_{2}$.

On the other hand, for $\mathrm{NaSbS}_{2}$, the phase stability condition is given by

$\mu_{\mathrm{Na}}+\mu_{\mathrm{Sb}}+2 \mu_{\mathrm{S}}=\Delta H\left[\mathrm{NaSbS}_{2}\right]$

where $\Delta H\left[\mathrm{NaSbS}_{2}\right]$ is the heat of formation of $\mathrm{NaSbS}_{2}$. To avoid the formation of secondary phases, the following conditions should be applied

$3 \mu_{\mathrm{Na}}+\mu_{\mathrm{Sb}} \leq \Delta H\left[\mathrm{Na}_{3} \mathrm{Sb}\right]$,

$2 \mu_{\mathrm{Na}}+\mu_{\mathrm{S}} \leq \Delta H\left[\mathrm{Na}_{2} \mathrm{~S}\right]$,

$2 \mu_{\mathrm{Sb}}+3 \mu_{\mathrm{S}} \leq \Delta H\left[\mathrm{Sb}_{2} \mathrm{~S}_{3}\right]$

$3 \mu_{\mathrm{Na}}+\mu_{\mathrm{Sb}}+3 \mu_{\mathrm{S}} \leq \Delta H\left[\mathrm{Na}_{3} \mathrm{SbS}_{3}\right]$,

where $\Delta H\left[\mathrm{Na}_{3} \mathrm{Sb}\right], \Delta H\left[\mathrm{Na}_{2} \mathrm{~S}\right], \Delta H\left[\mathrm{Sb}_{2} \mathrm{~S}_{3}\right]$, and $\Delta H\left[\mathrm{Na}_{3} \mathrm{SbS}_{3}\right]$ are the heat of formation of $\mathrm{Na}_{3} \mathrm{Sb}_{2} \mathrm{Na}_{2} \mathrm{~S}, \mathrm{Sb}_{2} \mathrm{~S}_{3}$, and $\mathrm{Na}_{3} \mathrm{SbS}_{3}$. With all of these conditions, a range of chemical potentials for NaSbS2 is plotted in Figure $\mathrm{S}_{3}$. 


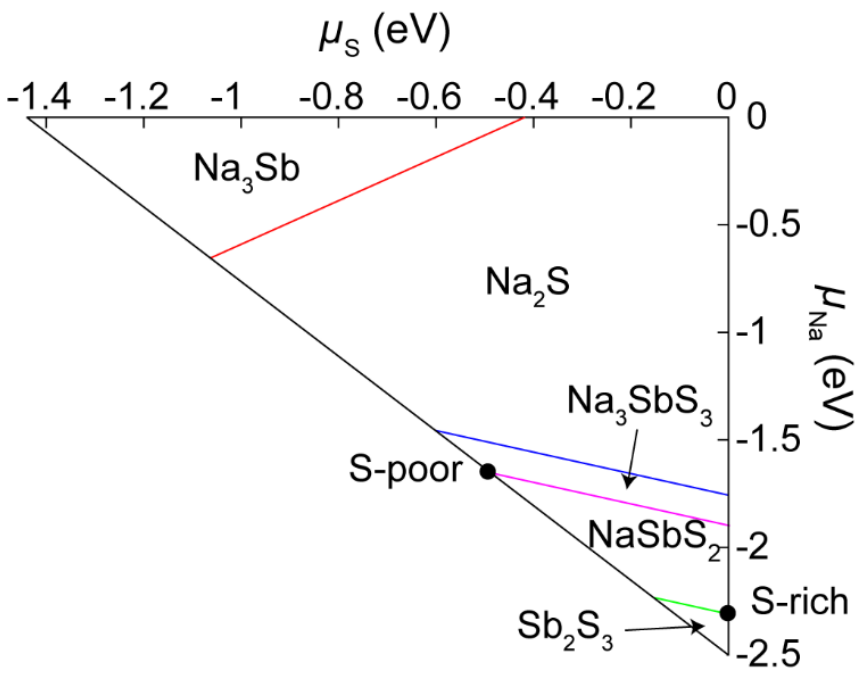

Figure S3. Stability regions of different compounds with respect to S and Na chemical potentials. Black dots represent the S-rich and S-poor conditions which are used to compute defect formation energies in Figure 5 in the main text. 